\title{
Potentiometric Membrane Sensors for Determination of Memantine Hydrochloride and Pramipexole Dihydrochloride Monohydrate
}

\author{
Hanan A. Merey, ${ }^{a,}{ }^{*}$ Marwa I. Helmy, ${ }^{b}$ Shereen M. Tawakkol, ${ }^{b}$ \\ Safaa S. Toubar ${ }^{b}$ and Mohamed S. Risk ${ }^{a}$ \\ ${ }^{a}$ Analytical Chemistry Department, Faculty of Pharmacy, Cairo University, Kasr El Aini st., \\ 11562-Cairo, Egypt \\ ${ }^{b}$ Analytical Chemistry Department, Faculty of Pharmacy, Helwan University, Ain Helwan, \\ 11790-Cairo, Egypt
}

Received 29 January 2012; accepted 28 February 2012

\begin{abstract}
Five solid membrane sensors responsive to memantine hydrochloride (MEM) and pramipexole dihydrochloride monohydrate (PXL) are described for simple and fast determination of these drugs in pharmaceutical preparation and human plasma. The first and the second sensors are based on the formation of an ion association complex between MEM as a cationic drug with Na tetra phenyl borate and ammonium reineckate (as anionic exchanger), respectively. The third sensor is based on the formation of an ion association complex between PXL with ammonium reineckate. The produced electroactive material is dispersed in PVC matrix. While the other fourth and fifth sensors are based on using functionalized lipophilic cyclodextrin derivative (2-hydroxypropyl- $\beta$-cyclodextrin) as sensor ionophore for the determination of MEM and PXL. The performance characteristics of these sensors-evaluated according to IUPAC recommendations-reveal fast, stable and near Nernstian response for $1 \times 10^{-4}-1 \times 10^{-1}$ $\mathrm{M}$ and $1 \times 10^{-6}-1 \times 10^{-2} \mathrm{M}$ for (MEM) and (PXL), respectively. Many inorganic and organic substances such as drug excipients and diluents normally used in drug formulations do not interfere with drugs response. Statistical comparison between the results obtained by applying the proposed potentiometric method for the determination of the (MEM) and (PXL) in their pure powder forms and those obtained by applying the reported methods was done and no significant difference was found at $p_{=} 0.05$. Validation of the method according to ICH guidelines shows the suitability of the sensors for quality control analysis of the cited drugs in pharmaceutical formulations and human plasma. The proposed sensors can also be used as a detector for HPLC.
\end{abstract}

Keywords: memantine hydrochloride, pramipexol dihdydrochloride, membrane sensors, potentiometry.

\footnotetext{
* Corresponding author. E-mail bibatofa@yahoo.com
} 


\section{Introduction}

Parkinson's disease is the most common neurodegenerative movement disorder disease, which affects the part of the brain that controls muscle movement. The major clinical symptoms include rigidity, tremors and slowed movement. These symptoms respond well to dopaminergic therapy [1]. Memantine hydrochloride (MEM) and pramipexol dihydrochloride monohydrate (PXL) are CNS acting drugs. They are used for treatment of Parkinson's disease. MEM produces its effect through the blockade of current through channels of N-methyl-D-aspartate receptors broadly involved in brain function, while PXL is a dopamine agonist recently approved for the early and advanced Parkinson's disease [2].

Different techniques are used for the determination of MEM, including HPLC [315], gas chromatography coupled to mass spectrometry (GC-MS) [16], capillary zone electrophoresis [17-18], potentiometry [19], polarography [20] and spectrophotometry $[21,22]$, while PXL can be quantitatively estimated by HPLC [23-29], GC-MS [30], capillary zone electrophoresis [31] and spectrophotometric methods [32-34].

The aim of this work is to develop simple membrane sensors that can be used for the determination of MEM and PXL as a pure drug, in pharmaceutical dosage forms and in spiked human plasma.

\section{Experimental}

Apparatus

All potentiometric measurements were made at $25^{\circ} \mathrm{C}$.

A Jenway digital ion analyzer model 3503 (Essex, UK) with $\mathrm{Ag} / \mathrm{AgCl}$ double junction reference electrode No. Z113107-1EAPW (Steinhum, Germany) was used. The influence of $\mathrm{pH}$ on the response of the electrodes was studied using a $\mathrm{pH}$ glass electrode Jenway (Jenway, UK) No. 924005-BO3-Q11C. The determination of the samples occurred using a magnetic stirrer, Bandelin Sonorox, Rx510S (Budapest, Hungaria). Silver wire of $1.0 \mathrm{~mm}$ diameter was purchased from Fluka (Steinheim, Germany) and used as internal reference electrode in the constructed electrodes.

\section{Pure samples}

- Memantine hydrochloride: kindly supplied by SIGMA Co., Cairo, Egypt. The purity of MEM was found to be $99.04 \pm 0.717$ according to reported method [22].

- Pramipexol dihydrochloride monohydrate: kindly supplied by EVA PHARM Co., Cairo, Egypt. The purity of PXL was found to be 99.29 \pm 0.611 according to reported method [32].

\section{Market samples}

- Memexa tablets Batch No. 93151 labeled to contain $10 \mathrm{mg}$ MEM, produced by Marcyl pharmaceutical industries for Copadpharma, Cairo, Egypt.

- Ramixole tablets Batch No. 812802 labeled to contain 0.25 mg PXL, produced by EVA Pharm, Cairo, Egypt.

Memexa and Ramixole tablets were purchased from local market. 


\section{Reagents}

All chemicals and solvents used were of analytical grade (double- distilled water was used).

Nitrophenyloctyl ether was purchased from Aldrich (Steinheim, Germany). Poly vinyl chloride (PVC) high molecular weight, Poly vinyl chloride carboxylated (PVC-COOH) high molecular weight, $\beta$-cyclodextrin ( $\beta$-CD), 2-hydroxypropyl$\beta$-cyclodextrin (2-HP- $\beta$-CD), Ammonium reineckate, Tetra phenylborate and Dibutyle sebathate were purchased from Fluka (Steinheim, Germany), while Terahydrofuran, 99\% was obtained from $\mathrm{BDH}$ (Poole, England). $\mathrm{KCl}, \mathrm{HCl}$ and $\mathrm{NaOH}$ were obtained from Prolabo (Pennsylvania, USA). Fresh human plasma obtained from blood bank (VACSERA, Cairo, Egypt) was used within $24 \mathrm{~h}$. Acetate buffer $\mathrm{pH} 6.0$ and $\mathrm{pH} 4.0$ were prepared according to BP [35].

\section{Standard solutions for linearity}

- Stock solutions of MEM and PXL $\left(1 \times 10^{-1} \mathrm{M}\right)$ and working solutions of MEM $\left(1 \times 10^{-2}-1 \times 10^{-4} \mathrm{M}\right)$ and PXL $\left(1 \times 10^{-2}-1 \times 10^{-6} \mathrm{M}\right)$ were prepared in acetate buffer and in double distilled water.

\section{Procedures}

Preparation of memantine $\mathrm{HCl}$ ion exchangers: (sensors 1 and 2)

The ion-pair complexes of MEM-tetraphenylborate and MEM-ammonium reineckate were prepared by slow addition of $20 \mathrm{~mL} 1 \times 10^{-2} \mathrm{M}$ aqueous solution of MEM to $20 \mathrm{~mL} 1 \times 10^{-2} \mathrm{M}$ Na-tetraphenyl borate solution (sensor 1) or ammonium reineckate solution (sensor 2) with stirring. The resulting precipitates were filtered using Whatmann No 42 filter paper, washed with cold water, dried at room temperature (about $25^{\circ} \mathrm{C}$ ) and grinded to fine powders.

In a Petri dish (5 cm diameter), $0.01 \mathrm{~g}$ of ion pair complexes was mixed thoroughly with $0.19 \mathrm{~g}$ of PVC, $0.35 \mathrm{~g}$ nitrophenyloctyl ether and $5 \mathrm{~mL}$ THF. The dish was covered with a filter paper and left to stand overnight to allow slow evaporation of the solvent forming the master membrane with $0.1 \mathrm{~mm}$ thickness [36].

Preparation of 2-hydroxypropyl- $\beta$-cyclodextrin (2-HP- $\beta C D)$ membrane (sensors 3 and 4)

$0.04 \mathrm{~g}$ 2- HP- $\beta C D, 0.4 \mathrm{~g}$ nitrophenyloctyl ether (sensor 3) or $0.4 \mathrm{~g}$ dibutyl sebacate (sensor 4) and $0.18 \mathrm{gm}$ PVC-COOH were mixed and dissolved with 5 $\mathrm{mL}$ THF in a Petri dish $(5 \mathrm{~cm}$ diameter). The dish was covered with a filter paper and left to stand overnight to allow slow evaporation of the solvent forming the master membrane with $0.1 \mathrm{~mm}$ thickness.

Preparation of pramipexole dihydrochloride monohydrate ion exchanger: (sensor 5)

The ion-pair complex of pramipexole -ammonium reineckate was prepared by slow addition of $20 \mathrm{~mL} 1 \times 10^{-2} \mathrm{M}$ aqueous solution of pramipexole dihydrochloride monohydrate to $20 \mathrm{~mL} 1 \times 10^{-2} \mathrm{M}$ aqueous solution of ammonium 
reineckate solution with stirring. The resulting precipitate was filtered using Whatmann No 42 filter paper, washed with cold water, dried at room temperature (about $25^{\circ} \mathrm{C}$ ), and grinded to a fine powder.

$0.01 \mathrm{~g}$ of ion pair complex was mixed in a Petri dish $(5 \mathrm{~cm}$ diameter $)$, thoroughly with $0.19 \mathrm{~g}$ of PVC, $0.35 \mathrm{gm}$ nitrophenyloctyl ether and $5 \mathrm{~mL}$ THF. The dish was covered with a filter paper and left to stand overnight to allow slow evaporation of the solvent forming the master membrane with $0.1 \mathrm{~mm}$ thickness.

\section{Electrode assembly}

A disk of appropriate diameter (about $8 \mathrm{~mm}$ ) was cut from the previously prepared master membranes and cemented to the flat end of the PVC tubing with an adhesive of PVC dissolved in tetrahydrofuran. The other end of the PVC tubing was cemented to an appropriate glass outer casing. A mixture of equal volumes of $1 \times 10^{-2} \mathrm{M}$ MEM or $1 \times 10^{-2} \mathrm{M}$ PXL with $1 \times 10^{-2} \mathrm{M}$ potassium chloride was used as an internal reference solution for the determination of MEM or PXL, respectively. The membranes were conditioned by soaking in $1 \times 10^{-2} \mathrm{M}$ drug solution for 24 hours and stored in the same solution when not in use.

\section{Sensors calibration}

The prepared sensors were immersed in conjunction with the double junction $\mathrm{Ag} / \mathrm{AgCl}$ reference electrode in working solutions of MEM or PXL in the range of $1 \times 10^{-4}-1 \times 10^{-1} \mathrm{M}$ or $1 \times 10^{-6}-1 \times 10^{-2} \mathrm{M}$, respectively. The membrane sensors were washed between measurements with double distilled water. The emfs were recorded as a function of the drug concentrations, then the calibration graphs of the recorded potentials vs. -log drug concentrations were plotted. These calibration graphs or the computed regression equations for the linear part of the curves were used for the subsequent determination of unknown concentrations of MEM or PXL.

\section{Application to pharmaceutical formulations}

- For MEM: Fifteen tablets of the drug formulation were accurately weighed and powdered. An accurately weighed portion of the powder equivalent to 0.215 gm MEM was dissolved in $100 \mathrm{~mL}$ acetate buffer to prepare $1 \times 10^{-2} \mathrm{M}$ solution; then serial dilution to $1 \times 10^{-4} \mathrm{M}$ was done.

- For PXL: Thirty tablets of the drug formulation were accurately weighed and powdered. An accurately weighed portion of the powder equivalent to $0.003 \mathrm{gm}$ PXL was dissolved in $100 \mathrm{~mL}$ water to prepare $1 \times 10^{-4} \mathrm{M}$ solution; then serial dilution to $1 \times 10^{-6} \mathrm{M}$ was done.

The emf produced by immersing the prepared electrodes in conjunction with the double junction $\mathrm{Ag} / \mathrm{AgCl}$ reference electrode in the prepared solutions was recorded and the concentration of the drugs was computed from the corresponding regression equations.

\section{Application to human plasma}

Accurately weighed portions of pure drug of MEM and PXL were weighed and dissolved in $50 \mathrm{~mL}$ human plasma to obtain $1 \times 10^{-2} \mathrm{M}$ drug solution; then serial 
dilution was made followed by recording the emfs produced by immersing the prepared electrodes in conjunction with the double junction $\mathrm{Ag} / \mathrm{AgCl}$ reference electrode in the prepared solutions, and the concentration of MEM or PXL was computed from the corresponding regression equation.

\section{Results and discussion}

Ion selective electrodes play an important role in pharmaceutical analysis due to their simplicity, rapidity and accuracy over some other analytical methods like spectrophotometry and HPLC [36]. In addition, analytes in colored, turbid and viscous samples can be determined accurately using ion selective electrodes. They show rapid response to changes in the concentration. Furthermore, they may be used for the measurement over a wide concentration range. Ion selective electrodes are generally tolerant to small changes of $\mathrm{pH}$. A further advantage is that they are relatively simple and not expensive to develop, set up and run.

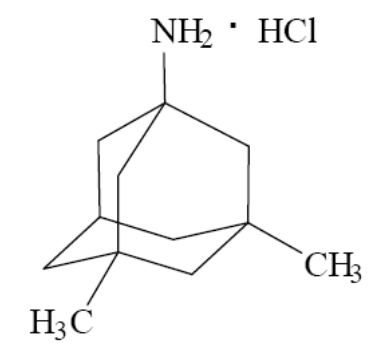

Figure 1. Structure of memantine $\mathrm{HCl}$.

In the present work, MEM is a tricyclic amine structure (Fig. 1) that does not have any conjugation, therefore exhibiting a very poor UV absorption. Determination of MEM using spectrophotometric or HPLC methods requires derivatization which increases the difficulty of the method. Reviewing the literature shows that only one ion selective membrane electrode method was reported for the determination of MEM [19] and no electrodes were reported for PXL (Fig. 2).

Table 1: Elemental analysis of the proposed sensors.

\begin{tabular}{|c|c|c|c|c|}
\hline & \multirow[b]{2}{*}{ Parameter } & \multicolumn{3}{|c|}{ Elemental analysis } \\
\hline & & $\% \mathrm{C}$ & $\% \mathbf{H}$ & $\% \mathrm{~N}$ \\
\hline \multirow[b]{2}{*}{ Sensor 1} & Calculated\%* & 83.64 & 7.94 & 2.71 \\
\hline & Found \% & 83.08 & 8.00 & 2.44 \\
\hline \multirow[b]{2}{*}{ Sensor 2} & Calculated\% $\%$ & 38.58 & 5.22 & 19.65 \\
\hline & Found\% & 38.16 & 4.30 & 19.45 \\
\hline \multirow[b]{2}{*}{ Sensor 5} & Calculated\% $\% *$ & 25.47 & 3.42 & 24.70 \\
\hline & Found\% & 25.27 & 3.66 & 24.54 \\
\hline
\end{tabular}


Therefore, the object of this work was to develop simple, rapid, precise and accurate methods for the determination of MEM and PXL in pure form, pharmaceutical dosage forms and in plasma samples without any preliminary derivatization or extraction procedures.

Table 2. Electrochemical response characteristics of the investigated sensors.

\begin{tabular}{|c|c|c|c|c|c|}
\hline \multirow{2}{*}{ Parameter } & \multicolumn{3}{|c|}{ Memantine HCl } & \multicolumn{2}{c|}{ Pramipexole (HCl) $\mathbf{2}$} \\
\cline { 2 - 6 } & Sensor 1 & Sensor 2 & Sensor 3 & Sensor 4 & Sensor 5 \\
\hline Slope (mV/decade) & $59.34^{*}$ & $59.13^{*}$ & $57.80^{*}$ & $29.98^{* *}$ & $28.69^{* *}$ \\
\hline Intercept (mV) & 278.29 & 285.60 & 263.70 & 212.70 & 231.68 \\
\hline Response time (seconds) & 10 & 10 & 10 & 20 & 20 \\
\hline Working pH range & $2-8$ & $2-10$ & $2-10$ & $2-9$ & $2-6$ \\
\hline Concentration range (M) & $10^{-4}-10^{-1}$ & $10^{-4}-10^{-1}$ & $10^{-4}-10^{-1}$ & $10^{-6}-10^{-2}$ & $10^{-6}-10^{-2}$ \\
\hline Stability (days) & 30 & 30 & 30 & 21 & 21 \\
\hline Average recovery \% & 99.82 & 99.83 & 99.05 & 100.13 & 99.94 \\
\hline Standard deviation & 1.206 & 1.202 & 1.149 & 1.416 & 1.106 \\
\hline Correlation coefficient & 0.9998 & 0.9999 & 0.9999 & 0.9993 & 0.9997 \\
\hline
\end{tabular}

All the values were measured at temperature $\left(20-25^{\circ} \mathrm{C}\right)$. * Calculated by using 4 points. ** Calculated by using 5 points.

MEM and PXL behave as cations, due to the presence of primary, or primary and secondary, amine functional group in MEM or PXL, respectively. Therefore, tetraphenylborate and ammonium reineckate as anionic exchangers were used for construction of water insoluble ion-association complexes with these drugs (sensors 1,2 and 5). To investigate the effect of incorporation of hydroxypropyl$\beta$-cyclodextrin on the interaction properties between host and guest molecules, two other sensors (sensors 3 and 4) utilizing 2-hydroxypropyl-ß-cyclodextrin based technique were prepared and comparison of the results obtained with all membranes was done.

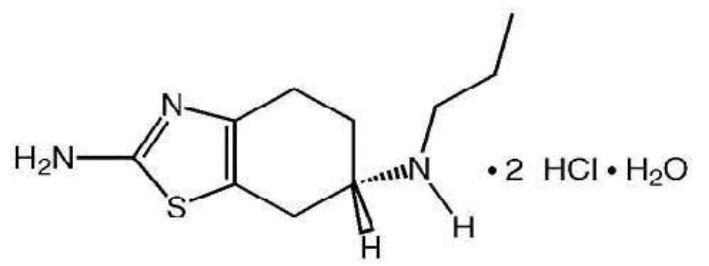

Figure 2. Structure of pramipexole $(\mathrm{HCl})_{2} \cdot \mathrm{H}_{2} \mathrm{O}$.

MEM reacts with tetraphenylborate and ammonium reineckate to form water insoluble 1:1 drug-ion association complexes, while PXL reacts with ammonium reineckate to form 1:2 association complex, as confirmed by elemental analysis, Table 1. This indicates that MEM and PXL behave as a univalent and bivalent species, respectively.

In this study, PVC was used in the fabrication of sensors 1, 2 and 5, while PVC$\mathrm{COOH}$ with $\mathrm{HP}-\beta-\mathrm{CD}$ was used in fabrication of the other proposed sensors (3 and 4). Nevertheless, the use of PVC or PVC-COOH creates a need for plasticization and places a constraint on the choice of the mediator [37].

Plasticizers play an important role in the behaviour of polymeric membrane ion selective electrodes. The introduction of polar or polarisable groups into 
membranes reduces the rate of exudation and therefore the loss of membrane components by their migration to the aqueous phase, which reduces the selectivity of membranes. Additionally, plasticizer viscosity and dielectric constant should be adequate.

It is well known that the sensitivity and selectivity of ion-selective electrodes strongly depend on the membrane compositions and the nature of the plasticizer used [38]. The nature of the plasticizer influences the dielectric constant of the membrane phase, the mobility of the ionophore molecules, and the forms of the ligands [39]. The effect of plasticizers was investigated using dibutyl sebathate and o-nitrophenyloctyl ether for the preparation of the proposed sensors. The electrochemical performance characteristics of the sensors were systematically evaluated according to IUPAC recommendations [40]. According to the results obtained, o-nitrophenyloctyl ether was found to be the most effective. This indicates that o-nitrophenyloctyl ether adjusts both the membrane permitivity and the mobility of the ion-exchanger sites to facilitate the inclusion of organic molecules by competitive inclusion and gives the optimal selectivity and sensitivity [41]. Polar plasticizers (o-nitrophenyloctyl ether) were reported to make the membrane more selective compared with nonpolar plasticizers (dibutyl sebathate) [42]. Therefore, sensor 1 is superior than that prepared by Ganjali et al. [19] for the determination of MEM through ion pair complexation between MEM and tetraphenylborate using dibutyl phthalate as a plasticizer.
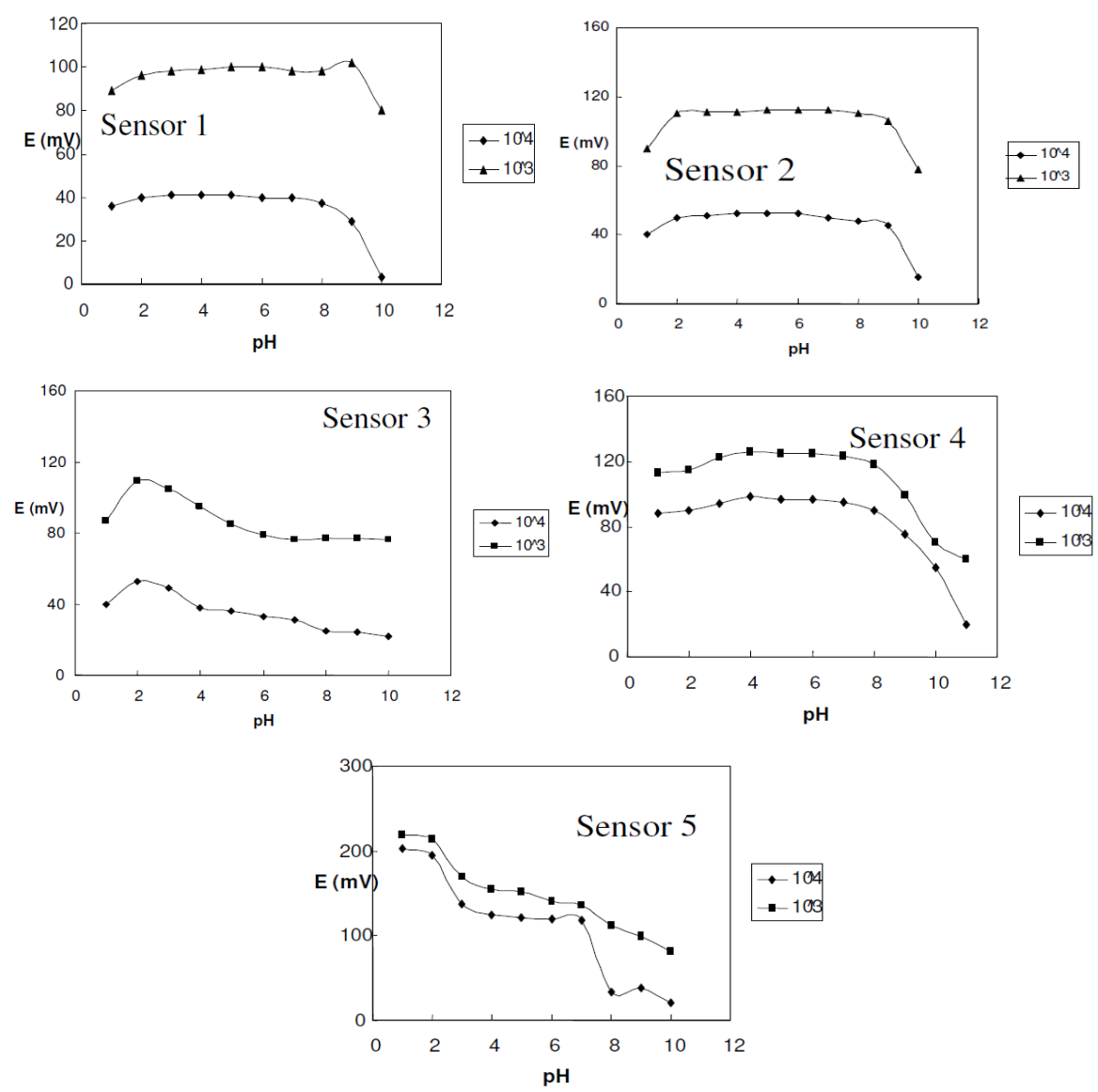

Figure 3. Effect of $\mathrm{pH}$ on the response of the prepared sensors. 
The response characteristics of the investigated sensors for memantine $\mathrm{HCl}$ and pramipexole dihydrochloride are summarized in Table 2. The sensors displayed constant potential readings within $\pm 2 \mathrm{mV}$ from day to day and the calibration slopes did not change by more than $\pm 2 \mathrm{mV}$ per decade over a period of 30 and 21 days for MEM and PXL sensors, respectively. The time required for the sensors to reach values within $\pm 1 \mathrm{mV}$ of the final equilibrium potential after increasing drug concentration 10 folds was found to be 10 to 20 seconds for MEM and PXL sensors, respectively. The slopes of calibration plots were 59.34, 59.13, 57.80 and 29.98, 28.69 for sensors 1-5, respectively. Deviation from Nernestian slope $(60$ or $30 \mathrm{mV}$ ) stems from the fact that the electrode responds to the activity of drug cation rather than its concentrations.

Table 3. Potentiometric selectivity coefficients $\left(\mathrm{K}^{\mathrm{Pot}}{ }_{\mathrm{i}, \mathrm{j}}\right)$ for the proposed sensors in the determination of memantine $\mathrm{HCl}$ and pramipexole $(\mathrm{HCl})_{2}$.

\begin{tabular}{|c|c|c|c|c|c|}
\hline \multirow{2}{*}{ Interferent } & \multicolumn{3}{|c|}{ Memantine HCl } & \multicolumn{2}{c|}{ Pramipexole $(\mathrm{HCl})_{2}$} \\
\cline { 2 - 6 } & Sensor 1 & Sensor 2 & Sensor 3 & Sensor 4 & Sensor 5 \\
\hline $\mathbf{N a C l}$ & $5.73 \times 10^{-3}$ & $5.95 \times 10^{-3}$ & $1.66 \times 10^{-3}$ & $1.91 \times 10^{-4}$ & $2.33 \times 10^{-5}$ \\
\hline KCl & $3.38 \times 10^{-3}$ & $3.31 \times 10^{-3}$ & $1.80 \times 10^{-3}$ & $3.27 \times 10^{-4}$ & $3.46 \times 10^{-5}$ \\
\hline Cellulose & $6.95 \times 10^{-4}$ & $3.58 \times 10^{-3}$ & $1.26 \times 10^{-3}$ & $6.52 \times 10^{-5}$ & $1.34 \times 10^{-5}$ \\
\hline Mg stearate & $5.95 \times 10^{-4}$ & $4.02 \times 10^{-3}$ & $1.21 \times 10^{-3}$ & $7.04 \times 10^{-5}$ & $5.22 \times 10^{-6}$ \\
\hline $\mathbf{S i O}_{\mathbf{2}}$ & $1.02 \times 10^{-3}$ & $2.72 \times 10^{-3}$ & $1.54 \times 10^{-3}$ & $4.12 \times 10^{-4}$ & $1.13 \times 10^{-4}$ \\
\hline Talc & $4.73 \times 10^{-4}$ & $3.31 \times 10^{-3}$ & $1.48 \times 10^{-3}$ & $8.86 \times 10^{-5}$ & $2.33 \times 10^{-5}$ \\
\hline Pregabaline & & & & $3.81 \times 10^{-4}$ & $9.06 \times 10^{-6}$ \\
\hline Mannitol & & & & $1.91 \times 10^{-5}$ & $4.82 \times 10^{-6}$ \\
\hline $\mathbf{N H}_{\mathbf{4}}$ acetate & & & & $6.53 \times 10^{-4}$ & $2.48 \times 10^{-4}$ \\
\hline Urea & & & & $8.86 \times 10^{-5}$ & $1.06 \times 10^{-5}$ \\
\hline Lactose & & & & $5.19 \times 10^{-5}$ & $1.06 \times 10^{-5}$ \\
\hline Starch & & & & $4.11 \times 10^{-5}$ & $8.38 \times 10^{-6}$ \\
\hline
\end{tabular}

Each value is the average of the three determinations. All interferents are in the form of $1 \times 10^{-3} \mathrm{M}$ solution.

Table 4. Results of analysis of Memexa ${ }^{\circledR}$ tablet and application of the standard addition technique to the determination of memantine $\mathrm{HCl}$ in Memexa ${ }^{\circledR}$ by the proposed sensors.

\begin{tabular}{|c|c|c|c|c|c|}
\hline $\begin{array}{c}\text { Memexa } \\
\text { tablets } \\
\text { Recovery \% } \\
\text { R.S.D. }\end{array}$ & $\begin{array}{c}\text { Claimed } \\
\text { amount taken }\end{array}$ & $\begin{array}{c}\text { Standard } \\
\text { added gm }\end{array}$ & $\begin{array}{c}\text { Recovery\% } \\
\text { using sensor 1 }\end{array}$ & $\begin{array}{c}\text { Recovery\% } \\
\text { using sensor 2 }\end{array}$ & $\begin{array}{c}\text { Recovery\% } \\
\text { using sensor3 }\end{array}$ \\
\hline $\begin{array}{c}98.80 \pm 0.571^{*} \\
99.69 \pm 0.733^{* *} \\
99.70 \pm 1.327^{* * *}\end{array}$ & \multirow{2}{*}{$1 \times 10^{-4} \mathrm{M}$} & 0.10593 & 98.61 & 103.18 & 98.52 \\
\cline { 3 - 6 } & & 0.53645 & 97.71 & 101.41 & 98.85 \\
\hline
\end{tabular}

* using sensor $1, * *$ using sensor 2 , *** using sensor 3 
The effect of $\mathrm{pH}$ on the potential values of the five electrodes systems over different $\mathrm{pH}$ range at $0.5 \mathrm{pH}$ intervals was studied by immersing the electrode in $1 \times 10^{-4}$ and $1 \times 10^{-3} \mathrm{M}$ aqueous solutions of MEM or PXL, respectively, and gradually increasing or decreasing the $\mathrm{pH}$ by adding aliquots of diluted sodium hydroxide or hydrochloric acid solutions, respectively, with constant stirring. The results obtained are shown in Fig. 3. Table 2 shows the optimum pH for each proposed sensor.

Table 5. Results of analysis of Ramixole $®$ tablet and application of the standard addition technique to the determination of pramipexole dihydrochloride in Ramixole ${ }^{\circledR}$ tablet by the proposed sensors.

\begin{tabular}{|c|c|c|c|c|}
\hline $\begin{array}{c}\text { Ramixole } ® \text { tablets } \\
\text { Recovery } \% \pm \\
\text { R.S.D. }\end{array}$ & $\begin{array}{c}\text { Claimed } \\
\text { amount taken }\end{array}$ & $\begin{array}{l}\text { Standard } \\
\text { added gm }\end{array}$ & $\begin{array}{c}\text { Recovery\% } \\
\text { using sensor } 4\end{array}$ & $\begin{array}{c}\text { Recovery\% } \\
\text { using sensor } 5\end{array}$ \\
\hline \multirow{3}{*}{$\begin{array}{l}101.02 \pm 0.692 * \\
98.22 \pm 0.618 * *\end{array}$} & \multirow{3}{*}{$1 \times 10^{-5} \mathrm{M}$} & 0.00067 & 101.42 & 103.28 \\
\hline & & 0.0074 & 102.14 & 99.79 \\
\hline & & 0.07495 & 100.24 & 101.43 \\
\hline \multicolumn{3}{|c|}{ Mean \pm R.S.D. } & $101.27 \pm 0.959$ & $101.50 \pm 1.746$ \\
\hline
\end{tabular}

* using sensor $4, * *$ using sensor 5

Upon studying the effect of temperature, the proposed sensors exhibit slight gradual increase in their potentials as the temperature increases in the range 25$45{ }^{\circ} \mathrm{C}$; however the calibration graphs obtained at different temperatures were parallel. The limit of detection slopes and response time did not significantly change with variation of temperature, indicating reasonable stability of PVC membranes up to $35^{\circ} \mathrm{C}$.

Table 6. Determination of MEM and PXl in spiked human plasma by the proposed sensors.

\begin{tabular}{|c|c|c|c|c|c|}
\hline \multirow{2}{*}{$\begin{array}{c}\text { Concentration } \\
\text { added to plasma }\end{array}$} & \multicolumn{5}{|c|}{ Recovery\% \pm S.D.* } \\
\hline & Sensor 1 & Sensor 2 & Sensor 3 & Sensor 4 & Sensor 5 \\
\hline $1 \times 10^{-6}$ & & & & $100.26 \pm 0.321$ & $98.56 \pm 1.006$ \\
\hline $1 \times 10^{-5}$ & & & & $99.63 \pm 0.385$ & $98.99 \pm 0.402$ \\
\hline $1 \times 10^{-4}$ & $99 . \overline{83 \pm 0.486}$ & $100.03 \pm 0.423$ & $101 . \overline{80 \pm 1.519}$ & $98.69 \pm 0.963$ & $99.92 \pm 0.871$ \\
\hline $1 \times 10^{-3}$ & $100.52 \pm 0.858$ & $101.06 \pm 0.861$ & $101.13 \pm 1.451$ & $97.87 \pm 0.642$ & $101.09 \pm 0.671$ \\
\hline $1 \times 10^{-2}$ & $101.35 \pm 1.192$ & $101.98 \pm 1.196$ & $101.38 \pm 1.835$ & $98.44 \pm 0.963$ & $99.93 \pm 1.006$ \\
\hline
\end{tabular}

The selectivity coefficients of MEM and PXL were determined using the separate solution method [43], where potentials were measured for $10^{-3} \mathrm{M}$ aqueous MEM or PXL solution and then for $1 \times 10^{-3}$ interfering aqueous solution, separately; then the selectivity coefficients were calculated from the following equation [44]:

$$
\log \left(\mathrm{K}_{\text {primary ion, interferent }}\right)=\mathrm{E}_{2}-\mathrm{E}_{1} / \mathrm{S}
$$


where $E_{1}$ and $E_{2}$ are the potential readings observed after one minute from exposing the electrodes to the same concentration of the studied drug and the interferent, respectively, and $S$ is the slope of the investigated sensor $(\mathrm{mV} /$ concentration decade).

Table 7. Statistical analysis of the results obtained for determination of memantine $\mathrm{HCl}$ and pramipexole $(\mathrm{HCl})_{2}$ by the proposed ISE method and the manufacturer methods.

\begin{tabular}{|c|c|c|c|c|c|c|c|}
\hline \multirow{3}{*}{ Items } & \multicolumn{5}{|c|}{$I S E$} & \multicolumn{2}{|c|}{ Comparison methods } \\
\hline & \multicolumn{3}{|c|}{ MEM } & \multicolumn{2}{|c|}{ PXL } & \multirow{2}{*}{$\operatorname{MEM}^{(22) *}$} & \multirow{2}{*}{ PXL $^{(32) * *}$} \\
\hline & Sensor 1 & Sensor 2 & Sensor 3 & Sensor 4 & Sensor 5 & & \\
\hline Mean & 99.82 & 99.83 & 99.05 & 100.13 & 99.94 & 99.04 & 99.29 \\
\hline S.D. & 1.206 & 1.202 & 1.149 & 1.416 & 1.106 & 0.717 & 0.611 \\
\hline $\mathbf{N}$ & 4 & 4 & 4 & 5 & 5 & 5 & 5 \\
\hline $\mathbf{V}$ & 1.454 & 1.445 & 1.320 & 2.005 & 1.223 & 0.514 & 0.373 \\
\hline $\begin{array}{c}\text { Student's t } \\
\text { test }\end{array}$ & $\begin{array}{l}1.213 \\
(2.365)\end{array}$ & $\begin{array}{c}1.232 \\
(2.365)\end{array}$ & $\begin{array}{c}0.016 \\
(2.365)\end{array}$ & $\begin{array}{c}1.217 \\
(2.306)\end{array}$ & $\begin{array}{c}1.150 \\
(2.306)\end{array}$ & & \\
\hline F test & $\begin{array}{l}2.83 \\
(6.59)\end{array}$ & $\begin{array}{c}2.81 \\
(6.59)\end{array}$ & $\begin{array}{l}2.57 \\
(6.59)\end{array}$ & $\begin{array}{c}5.38 \\
(6.39)\end{array}$ & $\begin{array}{c}3.28 \\
(6.39)\end{array}$ & & \\
\hline
\end{tabular}

Figures between parenthesis are the corresponding tabulated values $(\mathrm{p}=0.05){ }^{*}$ Spectrophotometric method using 4, chloro-7-nitro-2, 1, 3-benzoxadiazole (NBD-Cl) in borate buffer $\mathrm{pH} 8.6$ followed by measuring absorbance at $475 \mathrm{~nm}$.** Direct spectrophotometric method at $260 \mathrm{~nm}$.

The small values of selectivity coefficient show no interference from these additives, indicating reasonable selectivity for MEM and PXL, Table 3.

Although the incorporation of HP- $\beta-C D$ was expected to increase the accuracy and selectivity of sensors 3 and 5, the results shown in Table 2 show that there is no significant difference in accuracy. Also, the selectivity coefficients shown in Table 3 show that sensor 5 is slightly more selective than sensor 4 for the determination of PXL, while there is no difference in selectivity between sensor 3 and sensors 1 and 2 for the determination of MEM.

The proposed sensors were successfully applied for the determination MEM and PXL in their pharmaceutical dosage forms (Memexa ${ }^{\circledR}$ tablets and Ramixole ${ }^{\circledR}$ tablet). The obtained results are listed in Tables 4 and 5. The validity of the proposed sensors was assessed by applying the standard addition technique and satisfactory results were obtained, Tables 4 and 5.

Table 6 shows the results obtained for the determination of MEM or PXL in spiked human plasma samples. It is clear from the results that a wide concentration range of the studied drugs could be determined by the investigated sensors and they gave stable results in slopes and $\mathrm{mV}$ reading as revealed by high precision and accuracy recovery results of spiked plasma samples. It is also clear from the results in Table 6 that PXL can be determined in lower concentration $0.284 \mu \mathrm{g} / \mathrm{mL}\left(1 \times 10^{-6} \mathrm{M}\right)$ than MEM. It should be noted that the reported paper by Ganjali et al. [19] did not investigate the suitability of the sensors for the determination of MEM in plasma, which is the first choice biological fluid that 
can be used for studying the pharmacokinetics, bioavailability and bioequivalence of the drugs.

Statistical comparison between the results obtained by applying the proposed sensors for the determination of MEM or PXL in the pure powder form and those obtained by applying the manufacturer methods was also done and no significant difference was found at $\mathrm{p}=0.05$, Table 7 .

\section{Conclusion}

The use of the proposed sensors offers the advantage of fast response, being capable of determining the studied drugs with reasonable selectivity, high stability, low cost, elimination of drug pretreatment or separation steps, over a wide concentration and $\mathrm{pH}$ range and also they provide a good solution for the low UV absorption of MEM. MEM and PXL can be successfully determined in pure powder, in dosage form and in human plasma using the proposed sensors. They can therefore be used for the routine analysis of the cited drugs in quality control laboratories or as a detector in HPLC method for determination of MEM instead of prior derivatization of MEM before injection.

\section{References}

1. S.C Sweetman, Martindale the complete drug reference, 3rd ed., The Pharmaceutical Press, London, UK, (2002) 1174.

2. S.M. Ford and S.S. Roach, Introductory Clinical Pharmacology, eight edition, Lippincott, William \&Wilkins, Tokyo, Japan (2008) 323.

3. R.F. Suckow, M.F. Zhang, E.D. Collins, M.W. Fischman and T.B. Cooper; J. Chromatogr. B 729 (1999) 217-224.

4. R.F. Suckow; J. Chromatogr. B 764 (2001) 313-325.

5. T.H. Duh, H.L. Wu, H.S. Kou and C.Y. Lu, J. Chromatogr. A 987(1-2) (2003) 205-209.

6. M.J. Koeberle, P.M. Hughes, C.G. Wilson and G.G. Skellern, J. Chromatogr. B 787 (2003) 313-322.

7. T.H. Duh, H.L. Wu, C.W. Pan and H.S. Kou, J. Chromatogr. A 1088 (2005) 175-181.

8. Y. Higashi and Y. Fujii; J. Chromatogr. Sci. 43 (2005) 213-217.

9. Y. Higashi, S. Nakamura, H. Matsumura and Y. Fujii, Biomed. Chromatogr. 20 (2006) 423-428.

10. J.H. Chen, X.Y. Deng and Y.N. Zhong, Yaowu Fenxi Zazhi 26(9) (2006) 1325-1327, through Anal. Abstr, G 203, 69, 2007.

11. C. Shuangjin, F. Fang, L. Han and M. Ming, J. Pharm. Biomed. Anal. 44 (2007) 1100-1105.

12. A. A. Almeida, D. R. Campos, G. Bernasconi, S. Calafatti, F. A. P.Barros, M. N. Eberlin, E. C. Meurer, E. G. Paris and J. Pedrazzoli; J. Chromatogr. B 848 (2007) 311-316.

13. R.-N. Pan, T.-Y. Chan, B.P.-C. Kuo and L.-H. Pao, Chromatographia 70 (2009) 783-788. 
14. S.K. Dubey, A. Patni, A. Khuroo, N.R. Thudi, S. Reyar, A. Kumar, J.S. Tomar, R. Jain, N. Kumar and T. Monif, J. Chem. 6 (2009) 1063-1070.

15. A. Zarghi, A. Shafaati, S.M. Foroutan, A. Khoddam and B. Madadian, Sci. Pharm. 78 (2010) 847-856.

16. H.J. Leis, G. Fauler and W. Windischhofer, J. Mass Spectrometry 37 (2002) 477-480.

17. N. Reichova, J. Pazourek, P. Polaskova and J. Havel, Electrophoresis 23 (2002) 259-262.

18. Y. Hsin-Huo, Y. Yuan-Han and C. Su-Hwei, Electrophoresis 31 (2010) 1903-1911.

19. M.R. Ganjali, F. Aboufazeli, S. Riahi, R. Dinarvand, P. Norouzi1, M.H. Ghasemi, R. Kiani-Anbuhi and S. Meftah, Int. J. Electrochem. Sci. 4 (2009) 1138-1152.

20. C.Y. Lang, M.H. Wang and X.X. Zhu, Fenxi-Shiyanshi 21 (2002) 21-23.

21. V. Jagathi, B. Anupama, P. Sai Praveen and G. Devala, Int. J. Curr. Pharm. Res. 2 (2010) 17-18.

22. K. Michail, H. Daabees, Y. Beltagy, M. Abdel-Kkalek and M. Khamis, Int. J. Pharm. Pharm. Sci. 3 (2011) 180-185.

23. Y.Y. Lau, G.D. Hanson and N. Ichhpurani, J. Chromatogr. B 683 (1996) 217-223.

24. Y.Y. Lau, J.M. Selenka, G.D. Hanson, R. Talaat and N. Ichhpurani, J. Chromatogr. B 683 (1996) 209-216.

25. G. Srinubabu, K. Jaganbabu, B. Sudharani, K. Venugopal, G. Girizasankar and J.V.L. N.S. Rao, Chromatographia 64 (2006) 95-100 .

26. D.B. Pathare, A.S. Jadhav and M.S. Shingare, J. Pharm. and Biomed. Anal. 41 (2006) 1152-1156.

27. R.V.S. Nirogi, J. Biomed. Chromatogr. 21 (2007) 1151-1158.

28. M. Yadav, R. Rao, H. Kurani, J. Rathod, R. Patel, P. Singhal, P.S. Shrivastav, J. Chromatogr. Sci. 48 (2010) 811-818.

29. S. Humaira, A. Dey, S.A. Raju and S. Sanaullah, Der Pharmacia Lettre 2 (2010) 315-325.

30. J.G. Panchal, R.V. Patel, S.K. Menon, Biomed. Chromatogr. 25 (2011) 524530.

31. A. Musenga, E. Kenndler, E. Morganti, F. Rasi and M.A. Raggi, Anal. Chim. Acta 626 (2008) 89-96.

32. G.S. Babu and Ch.A.I. Raju, Asian Journal of Chemistry 19 (2007) 516818.

33. B.M. Gurupadayya, V. Vishwajith and N. Srujana, World Journal of Chemistry 4 (2009) 157-160.

34. N. Jain, R. Jain, S. Kulkarni, D.K. Jain and S. Jain, J. Chem. Pharm. Res. 3 (2011) 548-552.

35. British Pharmacopoeia, Vol. II, The Stationary Office, London (2007).

36. M.R. Ganjali, M. Hariri, S. Riahi, P. Norouzi and M. Javaheri, Int. J. Electrochem. Sci. 4 (2009) 295.

37. H. James, G. Carmack and H. Freiser, Anal. Chem. 44 (1972) 856-861.

38. E. Bakker, P. Buhlmann and E. Pretsch, Electroanalysis 11 (1999) 915. 
39. X. Yang, N. Kumar, H. Chi, D.D. Hibbert and P.N.W. Alexander, Electroanalysis 9 (1997) 549.

40. IUPAC Analytical Chemistry Division, Commission on Analytical Nomenclature, Pure Applied Chem. 72 (2000) 1852-1856.

41. V.K. Gupta, A.K. Singh, S. Mehtab and B. Gupta, Anal. Chim. Acta 566 (2006) 5.

42. A.M. EL-Kosasy, M.Y. Salem, M.G. EL-Bardicy, M.K. Abdelrahman, J. AOAC Int. 92 (2009) 1631.

43. G. Moody and J. Thomas, Selective Ion Sensitive Electrodes, Merrow Technical Library, (1971) Chapter 1.

44. T.S. Ma and S.S. M. Hassan, Organic Analysis Using Ion-Selective Electrodes, (1982) Academic press, London, New York. 